\title{
THE ROLE OF THE ANAESTHETIST IN THE POSTANAESTHETIC PERIOD*
}

\author{
LEONARD C. JENKINS, B.A., M.D., C.M., F.R.C.P.(C), \\ W. A. Dodds, M.D., AND H. B. Graves, B.A., M.D., C.M. $\dagger$
}

\author{
All's Well That Ends Well \\ SHAKESPEARE (1601) \\ If the End is Good, All Will Be Good \\ GESTA ROMANORUM, TALE LXVII (1472)
}

IT WOULD SEEM to be an illogical sequence if the expert care of the anaesthetist for his patient in the operating room were abruptly abandoned the moment the anaesthetic was stopped, at a time when a rapid physiological transition is known to be taking place.

Perhaps the words of Sir Winston Churchill are appropriate here, when in 1942 he said: "Now this is not the end. It is not even the beginming of the end. But it is, perhaps, the end of the beginning."

The role of the anaesthetist in the postanaesthetic period has broadened. In an increasing number of instances, much more than the simple, single, social postanaesthetic visit is required of him; for he has become a highly qualified and valued consultant with special abilities, which make him a useful, and not uncommonly, an essential member of a therapeutic team.

This discussion deals in particular with clinical situations where these assets have been applied to the continued care of the surgical patient in the postanaesthetic period. The postanaesthetic recovery room has facilitated this care.

\section{Recovery Room at the Vancouver General Hosfital}

The postanaesthetic recovery room in the Heather Pavilion at the Vancouver General Hospital is situated adjacent to the operating suite and is under the supervision of the Department of Anaesthesia. Sixteen thousand patients are admitted each year. It consists of 22 beds, for 14 operating theatres. It is staffed by nine graduate nurses, with five rotating student nurses. There is 24 -hour coverage. The problems of long-stay post-surgical patients are of ten indistinguishable from those of intensive care of non-surgical patients. Hence, a special section of the recovery room has been provided for the intensive care of both types.

The existence of a postanaeśthetic recovery room does not exempt the anaesthetist from postanaesthetic problems; nor does it compensate for a poorly given anaesthetic. Its presence in an easily accessible location, staffed with spceial nursing personnel, provides for the early recognition and management of complications. Long-stay patients are followed more easily and meticulously. There

*Modified from an address to the Manitoba Division Meeting, Canadian Anaesthetists' Society, Winnipeg, October 10th, 1961.

†Department of Anaesthesia, Vancouver General Hospital and Faculty of Medicine, University of British Columbia, Vancouver, British Columbia. 
is freedom of consultation among the attending staff of other departments. Many patients require the attendance of a neurologist and internist, in addition to the surgeon and anaesthetist.

\section{The Postanaesthetic Recovery Room Call}

The problem call from the postanaesthetic recovery room nurse is most commonly for (1) acute respiratory difficulty, (2) hypotension, (3) pain, (4) nausea and vomiting.

\section{Acute "Respiratory Difficulty"}

A striking illustration of how "respiratory difficulty" can arise even during seemingly well-controlled conditions recently occurred in our recovèry room. A 56-year-old white female patient, with a fractured sixth cervical vertebra following a traffic accident, presented with respiratory insufficiency for emergency tracheostomy. Preoperative tidal volume with a Wright anemometer was $75-100 \mathrm{cc}$. A cuffed rubber James tube No. 11 was inserted through the tracheostomy. The patient was maintained or mechanically assisted intermittent positive pressure respiration (Bird). On the third postoperative day in the recovery room, laboured respirations were noted. The patient was restless and cyanotic. Breath sounds were absent over the left lung. A chest film demonstrated complete atelectasis of the left lung. The tracheostomy tube was not endobronchial, the lumen was patent. The Bird respirator was registering a satisfactory inflation pressure and "tripping" consistently. On examination it was found that adhesive tape, which had been wrapped around the metal angle piece as it attached to the corrugated rubber from the respirator, had slipped and almost occulded the orifice, preventing adequate positive pressure from reaching the patient's lungs. Following removal of this obstruction and subsequent mechanically assisted respiration, a repeat chest $\mathrm{X}$-ray demonstrated a marked improvement with a clear left lung field on the film.

\section{Hypotension}

The incidence of unwanted postoperative hypotension has been reported to be as high as 1 in every 31 patients. ${ }^{2}$ The most common causes of postanaesthetic hypotension fall into six main groups (Table I): cardıovascular, respiratory, pharmacological, neurogenic, haematological, and humoral.

An understanding of the physiological control of blood pressure is essential, to form a clearer understanding of the causative factors of hypotension. More accurate management of hypotension is then possible. Blood pressure is the lateral pressure exerted by the blood on the vessel wall. Its mean level is proportional to the product of the cardiac output and the peripheral resistance (vasomotor tone).

(a) Cardiac output is the product of the stroke volume and the heart rate. The cardiac output, in turn, depends on (i) the force of the heart and (ii) the cardiac filling or venous return.

(b) The peripheral resistance (vasomotor tone). The peripheral vascular resistance depends upon two factors: the viscosity of the blood and the total cross-sectional area of the available exit vessels, which varies according to (i) the anatomical 
TABLE I

Postanaesthetic Hypotension

\begin{tabular}{|c|c|}
\hline Cardiovascular & $\begin{array}{l}\text { 1. I Vasomotor tone } \\
\text { 2. I Cardiac output } \\
\text { (i) \Venous return } \\
\text { (ii) } \downarrow \text { Force contraction } \\
\text { (iii) Heart rate change }\end{array}$ \\
\hline Respiratory & $\uparrow \mathrm{pCO}_{2} \rightarrow \downarrow \mathrm{pCO}_{2}$ \\
\hline Pharmacological & $\begin{array}{l}\text { 1. Chlorpromazine } \\
2 \text { Opiate overdose } \\
\text { 3. Spinal anaesthesia }\end{array}$ \\
\hline Neurogenic (reflex) & Unrelieved pain \\
\hline Haematologual & $\begin{array}{l}\text { 1. Hypovolaemia (oligaemia) } \\
\text { 2. I/V haemolysis }\end{array}$ \\
\hline Humoral & $\Downarrow$ Adrenocortical steroids \\
\hline
\end{tabular}

state of the vessels, (ii) the nervous control, and (iii) the peripheral chemical and humoral effects on these vessels.

With these brief physiological considerations in mind, then, it follows that a fall in arterial pressure may be due to a reduced cardiac output, to reduced peripheral resistance (vasomotor tone), or a combination of these. These disturbances are classified in Table 1 .

The pulse rate is a useful key to the treatment of hypotension in the postanaesthetic period. (i) Hypotension associated with atrial tachycardia is usually due to reduction of the cardiae output, from a fall in the venous return. Treatment is to increase the venous return by posture or transfusion. Cardiac output may also fall owing to reduced force of cardiac contraction. This may be secondary to pharmacological depressant overdose or myocardial insufficiency of underlying heart disease. Treatment is directed to maintaining perfect oxygenation, promoting elimination of the depressant, and the use of cardiac and medullary stimulants. (ii) Hypotension with an unchanged pulse rate is probably due to reduction in peripheral resistance. The peripheral resistance may be increased by pressor drugs. Phenylephrine (Neosynephrine ${ }^{\circledR}$ ), $8 \mathrm{mg}$. in $500 \mathrm{cc}$. of 5 per cent glucose in distilled water run as an intravenous drip, is useful for this purpose. Empirical treatment based upon the use of vasopressors is contraindicated, ${ }^{2}$ unless there is clear evidence that vasodilation is present, associated with a normal blood volume. (iii) Hypotension with bradycardia may be due to vagal reflex action. Treatment consists in removing the precipitating cause and blocking the vagal efferents with atropine gr. 1/100 to gr. 1/50 intravenously.

\section{Pain}

We are known to the layman as the one who can spare him pain during surgery. The relief of postoperative pain is also in the domain of the anaesthetist. In addition, we are consulted in the symptomatic relief of pain in patients whom our medical and surgical colleagues cannot cure. Surely this is a challenge to us, not only on professional, but on humanitarian grounds.

A recent repor ${ }^{3}$ indicates that a significantly smaller dosage of opiates than 
was formerly thought effective relieves pain satisfactorily in the postanaesthetic period and that frequently barbiturate sedation is all that is required for comfort.

The psychogenic factor may assume importance in pain manifestations. The clinical entity of pain is complex. The distinction between a patient's pain perception threshold and his reaction to pain is often difficult. ${ }^{4}$

In the management of such a problem, particularly the inoperable chronic pain syndrome, new drugs advocated for their long-term analgesic, non-addicting features have been disappointing. ${ }^{5}$ It is felt that, to date, a combination of opiate and phenothiazine in the smallest dose ranges feasible is one of the better methods of managing acute and, particularly, chronic pain. This combination offers a reasonable pharmacological attack on the two major components of pain-the reaction and the perception threshold.

\section{Nausea and Vomiting}

Postanaesthetic sickness, in severe cases, can be incapacitating. Disturbances of fluid and electrolyte balance and disruption of some operative incisions may occur; successful corrective intra-aural and intraocular surgery may be endangered. A multitude of factors may act in the production of postoperative sickness. Some of the gross clinical initiating causes are summarized in Table II.

TABLE II

\begin{tabular}{|c|c|}
\hline Patient, "sickness prone" & $\begin{array}{l}\text { 1. Female } \\
\text { 2. Past history } \\
\text { 3. Sensitivity to opiate }\end{array}$ \\
\hline Anaesthetic agent & $\begin{array}{l}\text { 1. Ether } \\
\text { 2. Chloroform } \\
\text { 3. Cyclopropane } \\
\text { 4. Ephedrine }\end{array}$ \\
\hline Anaesthetic technique & $\begin{array}{l}\text { 1. } \uparrow \mathrm{pCO}_{2} \\
\text { 2 Hypoxia } \\
\text { 3. Air in stomach }\end{array}$ \\
\hline Surgery, site and type & $\begin{array}{l}\text { 1. Semicircular canals } \\
\text { 2. Vaginal }\end{array}$ \\
\hline
\end{tabular}

Exciting developments are taking place in the field of neuro-pharmacology. With precise anatomical and physiological pathways of central nervous connections being formulated, drugs with specific antagonistic or enhancing characteristics, acting at a specific site, are being investigated. For instance, it is now known that afferent and efferent pathways have intimate connections with the reticular activating system, the amygdaloid limbic system, branching out into a partially known emotional circle into the hypothalamus and connecting with the chemoreceptor trigger zone (CTZ) and vomiting centre. Already into this sphere have come the anti-emetics. The tranquillizing phenothiazine derivatives have proved most useful in the management of postanaesthetic sickness.

Certain of the phenothiazine derivatives are best, in that they specifically block impulses to central connections involved in vomiting. For example, ehlorpromazine (Largactil) is effective by its action on the hypothalamus, CTZ, and 
to a lesser extent the amygdaloid nucleus; promethazine (Phenergan) and perphenazine (Trilafon) act at the CTZ site.

Unfortunately, perphenazine, an excellent anti-emetic, also causes a high incidence $(65 \%)$ of extrapyramidal side-effects through its action at the amygdaloid area. This is true of all phenothiazine derivatives with a piperazine component. This includes prochlorperazine (Stemetil) and trifluoperazine (Stelazine). These extrapyramidal manifestations can be controlled and treated by giving. benadryl or cogentin.

Promethazine (Phenergan) is preferred because of its fairly high depressive specificity on the CTZ and to a lesser extent on the vomiting centre. The sedative effect and the rare occurrence of untoward side-effects such as hypotension, and severe depression, indicate that it is especially valuable in the postanaesthetic period. Where postoperative sickness is anticipated or its presence is particularly undesirable, promethazine is included in the preanaesthetic medication order, $25-50 \mathrm{mg}$. $1 \mathrm{hr}$. preoperatively intramuscularly or $2 \mathrm{hr}$. preoperatively orally in addition to the usual opiate and belladonna preparations; $25-50 \mathrm{mg}$. may also be given intramuscularly or intravenously just prior to completion of surgery.

\section{Special Surgical Patients Requiring Continled Supervision by Anaesthetists in the Postanaesthetic Period and Non-slrgical Patients Admited to the Postanaesthetic Recovery Room for InTEnsive CARE}

The patients fall into four main categories: (1) post cardiac arrest; (2) post open-heart surgery; (3) requiring hypothermia, i.e. head injuries, psychiatric; (4) respiratory insufficiency.

\section{Post Cardiac Arrest}

The physiological basis and method of management of these patients in our recovery room has been recently published. ${ }^{6}$

\section{Open Heart}

A detailed account of the role of the anaesthetist during open-heart surgery at Vancouver General Hospital has been reported. ${ }^{7}$ As was described there, two qualified anaesthetists and usually a senior resident manage the anaesthesia and the Lillihei-De Wall pump oxygenator during surgery. Tbere is a continuation of this team into the postanaesthetic period until the patient is considered stable, with regard to respiratory exchange, arterial and venous pressure, cardiac rate and rhythm, $\mathrm{pH}$, and $\mathrm{pCO}_{2}$.

On admission to the recovery room the patient is usually awake and resfw...... to spoken command. The patient is placed on mechanically assisted intermittent positive pressure respiration (Bird), by mask. Electrocardiograph leads are attached and Lead II tracing is recorded and observed on the oscilloscope. The blood volume balance is assessed with the final weighed sponge and drape count known. Consideration is given to the effect of haemodynamic changes occurring after the repair. Accordingly, blood is replaced as lost through chest drainage. Excessive bleeding is counteracted with hexadimethrine bromide (Polybrene, Abbott) following coagulation factor estimations. Sedation may be required. 
A tidal volume, minute volume by Wright anemometer, and $\mathrm{pH}, \mathrm{pCO}_{2}$, and $\mathrm{HCO}_{3}$ are determined every 15 minutes. If respiratory acidosis is apparent, the mechanical respirator is regulated as indicated. Chest expansion and lung aeration are carefully observed. A repeat $\mathrm{pH}$ and $\mathrm{pCO}_{2}$ is done within 15 minutes and ventilation is governed accordingly. If the biochemical determinations indicate metabolic acidosis, $\mathrm{NaHCO}_{3}$ is given intravenouslyl. $\mathrm{pH}$ and $\mathrm{HCO}_{3}$ determinations are repeated within $15-30$ minutes.

These patients have the complete attention of pne of the anaesthetists on the team for at least two hours and of ten for a longer period, especially if metabolic problems arise. They may be slow to regain complete consciousness, have a less stable cardiovascular status, and appear particularly prone to develop ventricular arrhythmias in the form of frequent ectopic beats, leading to bursits of ventricular tachycardia. These arrhythmias are corrected quickly, by intravenous dilantin $250 \mathrm{mg}$., repeated if necessary, or $\mathrm{NaHCO}_{3}$ if indicated. Hypotension associated with bradycardia may arise. In the absence of hypovolaemia, calcium gluconate may be needed or an intravenous drip of Isuprel $1: 200,000$ may be started. If the patient has not been digitalized preoperatively it may be necessary to do this at this time. If cerebral air embolism was suspected during surgery, thes patients may convulse in the postanaesthetic period. Intravenous thiopentone $(2.5 \%)$ is given initially for rapid control; dilantin and phenobartibal are used intramuscularly for prolonged stable management. Hypothermia may be initiated if convulsions become of a repetitive, uncontrollable nature. Intravenous urea may be employed.

It is apparent that many acute situations may develop in open-heart patients in the postanaesthetic period, requiring immediate attention and preferably prophylactic management. Care must be exacting and a thorough understanding of the defects involved and the surgical correction is demanded. The postanaesthetic period may be a critical period initially. Any let-down in the tean effort at this stage may prove disastrous to a patient who, with careful scrutiny, would have recovered. The anaesthetist, as an intimate member of the team, appears to fit the role well in the continued care of these surgical patients.

\section{Postanaesthetic Respiratory Insufficiency}

It is significant that the anaesthetist has not only become recognized and accepted, but that it is expected by his medical and surgical colleagues that he will manage these patients. ${ }^{8}$ The post-poliomyelitis and advanced emphysematous patients are two of the more common groups who may present problems of respiratory insufficiency in the postanaesthetic period. The treatment consists essentially of tiding the patient over until the limitations added by surgery resolve. In the absence of an obviously reversible complication, the patient with a chronic respiratory disorder, breathing inadequately after surgery to chest or abdomen, will usually require several days of respiratory assistance. Early recognition of this situation is therefore important. Repeated failed trials of spontaneous respiration frequently change a mild problem to a serious situation as a result of recurrent bouts of hypoxia and hypercarbia. ${ }^{8}$

The more intricate problems of respiratory insufficiency associated with patients with myasthenia gravis and tetanus are of special interest. 
Myasthenia gravis. The myasthenia gravis patient presents varied pharmacological and respiratory problems to the anaesthetist in the postanaesthetic period. ${ }^{9}$

It is important to avoid overenthusiastic prostigmine therapy in the postanaesthetic period as more patients have probably succumbed from overtreatment than from undertreatment. It is very easy to call all forms of respiratory distress "a myasthenic crisis" and assume that this calls for further anti-cholinesterase treatment. It is worth remembering that, in post-thymectomy patients, pain from the chest wound, pneumothorax, or haemothorax in one or both pleural cavities, ${ }^{10}$ a tension pneumothorax, atelectasis, are all possible sequelae. Before increasing the dosage of prostigmine the effect of a small intravenous dose (5-10 mg.) of edrophonium (Tensilon) should be determined. A brief but noticeable recovery may be taken as an indication for further prostigmine treatment. Oral treatment should be begun as early as possible. It is safer, the improvement in muscle power is better sustained, secretions are less marked, and overdosage is more difficult to produce.

The presence of even mild respiratory embarrassment after thymectomy is an indication for tracheostomy. This reduces the dead spaceland enables secretions to be removed easily. The "iron-lung" cabinet respirator fias no part to play in the modern treatment of the post-thymectomy patient. If assisted or controlled ventilation is required, an intermittent positive pressure ventilator should be used.

Tetanus. The very fact that tetanus is now seen rarely of ten means failure by the physician to recognize early symptomatology. Therefore, patients admitted to hospital with this disease very often have their muscles of respiration involved and have paroxysms of muscle spasms. They require tracheostomy, following which anaesthetists have been able to give practical help in the treatment of these individuals. Muscle relaxants are used to produce total paralysis, combined with controlled positive pressure respiration and central sedation. Here again is a dramatic example of a clinical problem requiring specialized knowledge of pharmacology and respiratory care for successful management.

In practice, it is the assessment of the progress of the disease, that suggests the form of treatment. The clinical picture may change in a matter of hours, let alone days. At the earliest stage, as soon as a tentative diagnosis is made, the administration of chlorpromazine would seem reasonable. Chlorpromazine has a number of actions of specific value in the treatment of tetanus. It depresses the internuncial neurones of the spinal cord when given in large doses. It depresses basal ganglia. The dosage must be large and fully adequate to control and prevent paroxysms (100-150 mg. intramuscularly every four to six hours, and seldom more than $1.0 \mathrm{gm}$. in 24 hours $^{11}$ ). In certain cases tracheostomy is indicated to avoid laryngeal crises in a patient particularly sensitive to such a complication. At the first sign that full control with chlorpromazine in combination with barbiturate or meprobamate is not possible, a muscle relaxant regime with full paralysis must be instituted. To delay and risk death from respiratory inadequacy during a paroxysm is dangerous and unnecessary.

Although radical treatment has undoubtedly led to a reduction in the mortality from severe tetanus, it is also unfortunately true that some cases die despite 
adequate control of their muscle spasms. This perhaps suggests that toxaemia or some long-lasting effect of the tetanus toxin-perhaps fixation of a lethal dose in the central nervous system-still plays a part in the severity of the disease.

Tracheo-oesophageal fistula. By far the most common cause of death in the postanaesthetic period of babies with corrected itracheo-esophageal fistula is a pulmonary complication. Early diagnosis is the best prophylaxis. However, very often these new-borns have been fed every four hours for one or two days before the anomaly has been recognized. Thus there is often regurgitation, bronchial obstruction, atelectasis, and pneumonia. This obstruction is corrected or improved, to a certain degree, by endobronchial suction prior to or just after endotracheal intubation at operation, when the collapsed lung is also inflated under positive pressure. This lung reaction is well entrenched, secretions and operative reaction continue into the postanaesthetic period. Thus similar problems in the lungs are prone to recur in the postanaesthetic period.

The single most effective way of managing these problems, both prophylactically and therapeutically, is by direct-vision postoperative endotreacheal, endobronchial suctioning with the patient awake, at least once daily for 4 to 7 days. This is most satisfactorily accomplished by using a short ureteral catheter (No. 6 or 7 ).

Recently, the facilities of our recovery room have been expanded to include special care of non-surgical patients. This group includes patients with crushed chest producing respiratory difficulties, chronic asthma in an acute attack, advanced pulmonary emphysema. These patients are logically managed in the recovery room because of the intensive nursing and medical care that they require. No doubt in the future other patients requiring prolonged intensive care will be included. Therefore, it is seen that the postanaesthetic recovery room easily adapts itself as an intensive care unit.

In order to assess and treat these cases adequately an Astrup Micro $\mathrm{pH}$ meter and $\mathrm{CO}_{2}$ analyser is used. This apparatus was chosen because of its ability to give rapid and repeated estimations of $\mathrm{pH}, \mathrm{pCO}_{2}$, and base excess according to the Astrup Nomogram. The readings are temperature-compensated to $38^{\circ} \mathrm{C}$. and require only a small quantity of blood such as is obtained from a finger prick.

Treatment of these cases, although somewhat similar, varies according to the cause of the respiratory difficulty. The acute asthmatic patient is admitted to the recovery room and may be confused, semi-comatose, restless, anoxic with an arterial oxygen saturation as low as 75 per cent and with a compensated respiratory acidosis. The $\mathrm{pH}$ may be as low as $7.2-7.3$, the $\mathrm{pCO}_{2} 75-150 \mathrm{~mm}$. $\mathrm{Hg}$, and standard bicarbonate 45-50 Meq./L. The treatment includes: (a) Intermittent positive pressure by means of a respirator to increase tidal volume. The tidal volume is monitored by a respirometer. (b) Sedation-required in the restless patient to facilitate nursing. $(c)$ Bronchoscopy or intubation to remove secretions and mucous plugs as an emergency procedure. (d) Tracheostomy is often preferable as it facilitates respirator control, suctioning, and reduces the dead space. (e) Biochemical control of the patient is constantly monitored, to assess efficiency of respiration by means of $\mathrm{pH}, \mathrm{pCO}_{2}$, and bicarbonate.

If the treatment is prolonged, other supportive therapy is required as regards: 
(a) Electrolyte control-due to intravenous therapy. Tube blender feeding is often more beneficial. (b) Cardiovascular control-digitalis and derivatives to treat failure. (c) Antibiotics-to minimize pulmonary infection. (d) Bronchodilators are usually indicated.

The chronic emphysematous patient may require treatment as outlined or may simply improve with judicious use of oxygen and careful electrolyte monitoring as outlined by Barach. ${ }^{12}$

The patient with a crushed chest and paradoxical respiration or difficult respiration may also be admitted to the recovery room intensive care unit. Some of these patients may have injuries more suitable to external fixation. The others are treated with: (a) Tracheostony, to facilitate suction, to facilitate respirator control with continuous positive pressure respiration, and to splint the thoracic cage. (b) Sedation is required initially so that the patient can tolerate respiratory control and pain from associated injuries. If the patient's ca-operation can be obtained, sedation may be gradually reduced. If the patient is un-cooperative because of older age group or a concomitant head injury, respiratory control may be difficult to obtain and curarization may be necessary. (c) Biochemical control is monitored to maintain the patient with a slight degree of respiratory alkalosis in order to minimize the $\mathrm{CO}_{2}$ effect on the respiratory centre. Further considerations in these patients are the recognition and treatment of haemothorax, pneumothorax, which may develop suddenly, and cardiac failure. The initial trauma may have affected the heart, producing a pericardial effusion and tamponade or even a complete heart block. These patients may require therapy for congestive failure. Cardiac arrhythmias are of ten troublesome. S- $T$ changes due to repeated bouts of anoxia may appear in the electrocardiogram. Atrial tachycardia is common and most often due to extra-cardiac causes, such as atelectasis. Electrolyte control is essential. Vascular compliçations măy occur. The blood volume should be restored and maintained. Venous thrombosis may occur as a result of prolonged bed rest and may be controlled by use of dicumarol and physiotherapy.

In our experience there are many problems associated with these cases. These problems are of two types: (a) Those associated with respiratory control, which are usually acute emergencies. These are mainly due to mechanical problems with the respirator or with the tracheostomy tube. (b) Those associated with prolonged bed care, which can be dealt with on a day-to-day basis. These include the routine nursing care, electrolyte balance, caloric intake, cardiovascular stability, etc. It is imperative that these problems be managed by specially trained nurses and readily available medical personnel with experience.

\section{The Importance of the Postanaesthetic Visit}

It is always gratifying to see the obvious pleasure that a patient shows from having the anaesthetist visit postoperatively. This in itself is a personally rewarding experience. However, apart from this, it is good public relations for our specialty, especially in an age with socialistic medical trends on the move. More important and to the point, it is good medicine. A routine postoperative observation and conversation with the patient may lead to the first step in the 
detection and prophylaxis of a possible serious complication. A striking illustration of a clinical situation that provides this opportunity is the thrombophlebitis to pulmonary embolism sequence. In our recent study ${ }^{13}$ we were surprised to find a postoperative mortality rate of 1 in 864 due to autopsy-proved pulmonary embolism. Over 90 per cent of these were sudden, single episodes. An awareness with regard to the embolic-prone individual, special attention to predisposing states, early recognition of postoperative thrombophlebitis leading to early anticoagulant therapy, may be important contributions on the part of anaesthetists in the reduction of morbidity and mortality from this complication.

Robert Louis Stevenson, the celebrated poet and author, in "Tribute to a Doctor'"14 expressed the following sentiment:

There are men and classes of men that stand above the common herd. The soldier, the sailor and the shepherd not infrequently; the artist rarely; rarer still, the clergyman, the physician almost as a rule. He is the flower (such as it is) of our civilization; and when that stage of man is done with, and only remembered to be marvelled at in history, he will be thought to have shared as little as any in the defects of the period, and most notably exhibited the virtues of the race. Generosity he has, such as is possible to those who practice an art never to those who drive a trade; discretion, tested by a hundred secrets; tact, tried in thousand embarrassments; and what are more important, Herculean cheerfulness and courage. So it is that he brings air and cheer into the sick room, and often enough, though not so of ten as he wishes, brings healing.

We would like to feel that we, as anaesthetists, have to the best of our ability justified the faith that men such as Robert Louis Stevenson have continued to place in us--that we as members of a therapeutic team in the postanaesthetic room and special care unit are making our contribution in the enhancement of healing.

\section{SLMMARY}

The anaesthetist's responsibility and interests are broadening. The role of the anaesthetist in the postanaesthetic period and his role in the management of special care patients in the postanaesthetic recovery room at Vancouver General Hospital is reviewed. The most common recovery room calls that may be associated with any surgical patient in the postanaesthetic period are for acute respiratory difficulty, hypotension, pain, nausea, and vomiting. There are special problems associated with the surgical patient after cardiac arrest and open-heart procedures. Problems of respiratory insufficiency may arise in the postanaesthetic period with patients having pre-existing chronic respiratory pathology associated with post-poliomyelitis, advanced emphysema, myasthenia gravis, and tetanus. In addition, intensive care by the anaesthetis̀t may be required in the management of respiratory insufficiency in patients with a crushed chest, chronic asthmatics with acute exacerbations, and in advanced pulmonary emphysema.

The anaesthetist with his special training in the management of respiratory failure and inadequacy, along with his knowledge of pharmacology, has a great deal to contribute as a useful and often indispensable member of the therapeutic team. 


\section{RÉSUMÉ}

La responsabilité et les intérêts de l'anesthésiste s'accroissent. Nous décrivons le rôle de l'anesthésiste au cours de la période post-anesthésique et son rôle dans les soins à donner à des malades spéciaux dans la salle de réveil post-anesthésique de l'hôpital Général de Vancouver. Les appels les plus fréquẹts auxquels nous avons à répondre dans la salle de réveil pour des opérés au cours de la période post-anesthésique, concernent des difficultés respiratoires soudaines, de l'hypotension, de la douleur, des nausées et des vomissements. Il existe des problèmes spéciaux posés par les opérés qui ont eu un arrêt cardiaque et ceux qui ont subi une opération à cœur ouvert. Les problèmes d'insuffisance respiratoire peuvent se rencontrer au cours de la période post-anesthésique chez des malades porteurs d'une pathologie respiratoire chronique pré-existante reliée à une ancienne poliomyélite, à un emphysème marqué, à une myasthénie grave et au tétanos. De plus, l'anesthésiste peut être demandé pour surveiller l'insuffisance respiratoire qui existe chez les traumatisés du thorax, chez les asthmatiques chroniques avec poussées aigues, et chez les grands emphysémateaux pulmonaires.

L'entraînement spécial qu'il possède dans le traitement de l'insuffisance et de l'arrêt respiratoires, ses connaissances en pharmacologie font que l'anesthésiste peut apporter une grande contribution à l'équipe thérapeutique et, de ce fait, il en devient un membre utile et souvent indispensable.

\section{REFERENCES}

1. Barbour, C. M. \& Little, D. M. J. Post-Operative Hypotension. J.A.M.A. 165: 1529) (1957).

2. Jenkins, L. C. \& Foulks, J. G. Effect of Norepinephrine in Irreversible Haemorrhagic Shock. Proc. West. Reg. Gp. N.R.C. 10 (Jan., 1956).

3. Beecher, H. K. The Measurement of Pain. Pharmac. Rev. 9 (March, 1957).

4. Wolff, H. G. \& Wolf, S. Pain, 2nd ed. Springfield, Ill.: C. C. Thomas (1958),

5. Boyd, R. H. A Clinical Trial of Dihydro-hydroxy Codeinone Pectinate. Anaesthesia 14: $144(1959)$.

6. Dodns, W. A., Jenkins, L. C.; \& Hersey, L. W. Management after Cardiac Arrest. Canad. Anaesth. Soc. J. 8: 561-567 (1961).

7. Dodds, W. A.; Graves, H. B.; Nixon, J. E.; Davies, L. E.; \& Sleath, G. E. The Anaesthetist's Role in Open Heart Surgery. Canad. Anaesth. Soc. J. 8: 239-246 (1961).

8. Fairley, H. Barrie \& Chambers, R. A. The Management of the Patient with Respiratory Insufficiency. Canad. Anaesth. Soc. J. 7: 447-490 (1960).

9. Harland, J. H. \& Stephen, C. R. Therapeutic Thymectomy, The Intensive Postoperative Care of the Severe Myasthenic Patient. Canad. Anlaesth. Soc. J. 5:323-329 (1958).

10. Chang, Jone; Harland, J. H.; \& Graves, H. B. Anaesthetic Aspect of Thymectomy for Myasthenia Gravis. Canad. Anaesth. Soc. J. 4: 13-20 (1957).

11. Laurence, D. R, et al. A Clinical Trial of Chlorpromazine against Barbituates in Tetanus. Lancet 1: 987 (1958).

12. Barách, V. Regulation of Pulmonary Ventilation in Pulmonary Emphysema. A.M.A. Int. Med. 108: 1256 (1959).

13. Jenkins, L. C. \& Graves, H. B. Anaesthesia and Pulmonary Embolism. Canad. Anaesth. Soc. J. 8: 143-153 (1961).

14. Stevenson, R. L. "Tribute to a Doctor": The Old Pacific Capital, from "Across the Plains." A Collection of Memories and Essays, The Monterey History and Art Association, H. C. Graham. Pacific Grove, Calif.: Pacific Grove Press (1956). 